\section{Clarity and versatility}

Diagnostic images are an important part of any treatment, so why not ensure you have a system that provides consistent clarity as well as versatility? The CS 8200 3D from Carestream Dental is a CBCT unit that has it all. Its ability to shift between 2D and 3D imaging means that it is an exceptional choice for a wide array of indications, while its extended field of view means that practices can easily extend their treatment capabilities.

Furthermore, the unit includes innovative CS MAR technology, helping to reduce metal artifacts so that images are predictably accurate and clear and the need for retakes is reduced. For more information, contact Carestream Dental on 08001699692 or visit www.carestreamdental.co.uk.

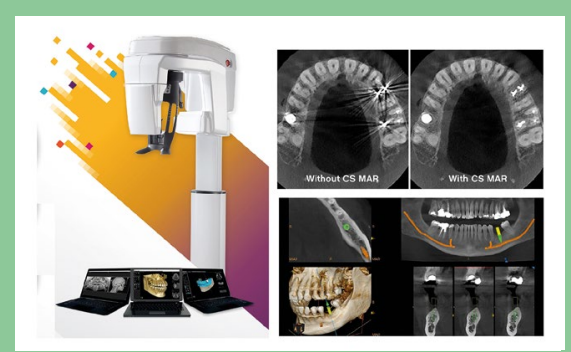

\title{
Good prevention starts with good brushing
}

TANDEX produces a range of brushes from the FLEXI interdental brush to UltraSoft options. TANDEX is adding international standard (ISO) passage hole diameter (PHD) numbers to its packaging. ISO number defines a range of PHD spaces the brush can be squeezed into without deformation and PHD number defines the specific space the product can be squeezed into.

Inside, each product has a specific colour to make selection of the right size brush for every patient easy and to facilitate optimal cleaning. TANDEX brushes are quality preventive tools that can help your patients avoid caries, why not try them?

For more information on Tandex's range of products, visit www.tandex.dk.

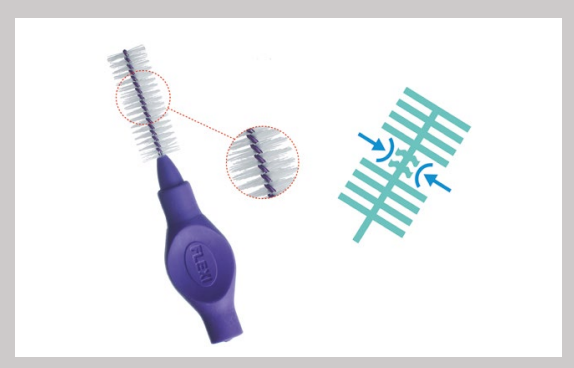

Revolutionise your

\section{workflow}

Revolutionise your workflow with the EXTARO 300 dental microscope, boasting a range of ground-breaking visualisation modes that include:

$\rightarrow$ Fluorescence Mode - Facilitates caries identification and treatment

$\rightarrow$ NoGlare Mode - Enables treatment without distracting reflections and accurate colour shading

$\rightarrow$ TrueLight Mode - Provides natural, white-light whilst retarding composite curing.

Designed with comfort in mind, the EXTARO 300 also features a Varioskop function and central control that can be used with a single finger to activate the microscope's visual and capture modes. This ensures you can maintain the most ergonomic working position to minimise the risk of strain and fatigue.

For more information call Nuview on 01453 872266, email info@nuview-ltd. com or visit www.nuview.co.uk.

\section{Backed by science}

As a dental professional, you want to be confident that the oral healthcare solutions patients use are backed by science.

The 'Perio plus' product range is the outcome of over 20 years' research and development, making it highly effective at combatting plaque and its associated complications. These solutions combine the benefits of chlorhexidine with those of Citrox - a natural bioflavonoid extracted from bitter oranges, featuring powerful anti-microbial properties. Clinically proven to afford greater efficacy than chlorhexidine alone, clinicians can recommend 'Perio plus' with total peaceof-mind that its pleasant-tasting formula promotes supreme patient compliance and safely ensures optimal results. ${ }^{1}$

For more information call 01480 862084, emailinfo@curaprox.co.uk or visit www.perioplus.com/uk.

\section{Reference}

1. Malic S, Emanuel C, Lewis M A O and Williams D W. Antimicrobial activity of nove mouthrinses against planktonic cells and biofilms of pathogenic microorganisms. Microbiology Discovery 2013; 1: 11 